\title{
Wilkinson Polynomials: Accuracy Analysis Based on Numerical Methods of the Taylor Series Derivative
}

\author{
Vera Mandailina ${ }^{1 *}$, Syaharuddin ${ }^{1 *}$, Dewi Pramita ${ }^{1}$, Malik Ibrahim $^{2}$, Habib Ratu Perwira \\ Negara $^{3}$ \\ ${ }^{1}$ Universitas Muhammadiyah Mataram, Indonesia \\ 2 Universitas Nahdlatul Ulama Mataram, Indonesia \\ ${ }^{3}$ Universitas Bumigora Mataram, Indonesia
}

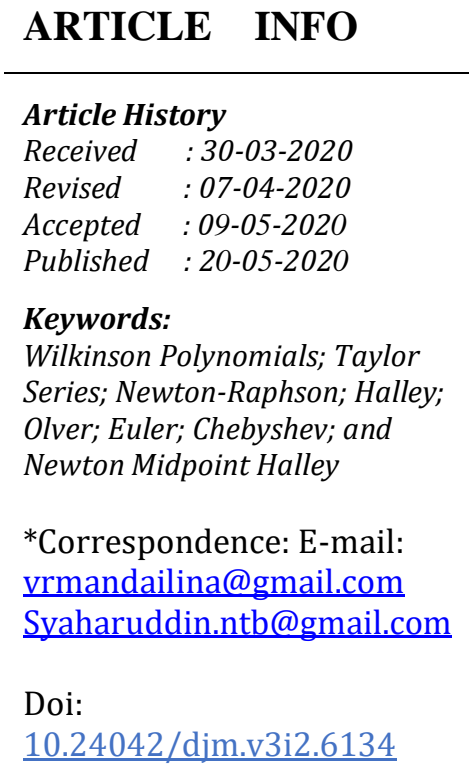

\begin{abstract}
Some of the numeric methods for solutions of non-linear equations are taken from a derivative of the Taylor series, one of which is the Newton-Raphson method. However, this is not the only method for solving cases of non-linear equations. The purpose of the study is to compare the accuracy of several derivative methods of the Taylor series of both single order and two-order derivatives, namely the Newton-Raphson method, Halley method, Olver method, Euler method, Chebyshev method, and Newton Midpoint Halley method. This research includes qualitative comparison types, where the simulation results of each method are described based on the comparison results. These six methods are simulated with the Wilkinson equation which is a 20-degree polynomial. The accuracy parameters used are the number of iterations, the roots of the equation, the function value $\mathrm{f}(\mathrm{x})$, and the error. Results showed that the Newton Midpoint Halley method was the most accurate method. This result is derived from the test starting point value of 0.5 to the equation root $\mathrm{x}=1$, completed in 3 iterations with a maximum error of 0.0001 . The computational design and simulation of this iterative method which are a derivative of the two-order Taylor series is rarely found in college studies as it still rests on the Newton-Raphson method, so the results of this study can be recommended in future learning.
\end{abstract}

http://ejournal.radenintan.ac.id/index.php/desimal/index

\section{INTRODUCTION}

The numerical method is one of the branches or areas of mathematics, especially engineering mathematics, which uses numbers to mimic the mathematical process (Alexandrov, 2018), (Pratamasyari, Silalahi, \& Guritman,
2017). One of the studies in numeric methods in resolving models or equations and a non-linear equation system using a variety of methods through complex and long calculations so that not very few use a tool in the form of software to simplify and minimize the calculation errors (Hakim \& 
Habibi, 2016), (Lim, Shin, Lim, \& Shin, 2013). Mathematical equations or models are needed to solve problems in various disciplines such as physics, chemistry, biology, economics, engineering fields (Krag, 2017), (Wilson, 2011). Simplified and linear mathematical models are often not representative to be applied in design or applied. Therefore, it is required a numerical solution for non-linear or polynomial degrees- $\mathrm{N}$ equations to be applied in a tangible way to such a design or applied field (Wigati, 2017).

Non-linear equations are forms with unnatural functions, can be exponent, logarithmic, polynomials, and trigonometry (Bakery \& Elmatty, 2017). So the process of determining nonlinear equations is an equation to find the root $\mathrm{x}$ so that $\mathrm{f}(\mathrm{x})=0$, this function does not have a specific formula so it needs to apply the numeric method to get its root value (Nur, 2018). Some methods that have been used can only be applied to certain degrees with an insufficient level of accuracy (Tentua, 2017).

The non-linear root settlement method can be done with a variety of methods such as Bisection, Secant, Fixed Point, Regula Falsi, and Newton-Raphson (Negara, 2018). These methods are generally introduced to students in universities because they have a simple and understandable algorithm. But the derived way of the Taylor series is not only those methods. From this study, it was stated that the Newton-Raphson method has the highest level of accuracy. However, other research results were explained that the Halley and Olver methods had a higher level of accuracy compared to the NewtonRaphson method (Pratamasyari, Silalahi, \& Guritman, 2017). Ironically, some methods with good and more accurate simulation results are still minimally mentioned in some references in the learning of numerical methods in colleges. If we look at the derived methods of the two-and three-order Taylor series, there is also Newton Midpoint Halley method which is a combination of NewtonRaphson and Halley methods, Euler's method, and the Chebyshev method. Therefore, these methods need to be initiated in a computing that is certainly in resolving non-linear equations. It aims to let us know the accuracy and speed of each method's iteration. Of course, these results can later be a recommendation in learning numerical methods in colleges.

Therefore, the research team aims to analyze the methods in terms of error percentages and the number of iterations resulting from the simulation performed, including comparing it to the NewtonRaphson method. The research team uses Matlab software to simplify the simulation to reduce calculation errors. This is because MATLAB is one of the reliable software in the numerical simulation process with a high degree of accuracy (Hasa \& Radoš, 2015), (Schmidt, 2010).

\section{METHOD}

This research includes qualitative comparison types, where this research compares simulation results between methods that have been used in delivering numeric method material that is NewtonRaphson method with methods that have never been or rarely taught to students, namely Halley's method, Newton Midpoint Halley, Olver, Euler, Chebyshev in resolving non-linear equations. This study used Wilkinson's polynomial equation as an equation to be determined its roots. The equation is.

$$
f(x)=x^{20}-210 x^{19}+20615 x^{18}-\ldots
$$

The formula for determining the root equation of the method is:

$$
\begin{aligned}
& \text { 1. Newton-Raphson Formula } \\
& x_{i+1}=x_{i}-\frac{f\left(x_{i}\right)}{f^{\prime}\left(x_{i}\right)}
\end{aligned}
$$

2. Method Halley Formula 
Desimal, 3 (2), 2020 - 157

Vera Mandailina, Syaharuddin, Dewi Pramita, Malik Ibrahim, Habib Ratu Perwira Negara

$$
x_{i+1}=x_{i}-\frac{f\left(x_{i}\right)}{f^{\prime}\left(x_{i}\right)-\frac{1}{2} f^{\prime \prime}\left(x_{i}\right) \cdot \frac{f\left(x_{i}\right)}{f^{\prime}\left(x_{i}\right)}}
$$

3. Newton Midpoint Halley Formula

$$
\begin{gathered}
x_{i+1}=\bar{x}_{i}-\frac{2 f\left(\bar{x}_{i}\right) f^{\prime}\left(\overline{x_{i}}\right)}{2\left(f^{\prime}\left(\bar{x}_{i}\right)\right)^{2}-f\left(\bar{x}_{i}\right) f^{\prime \prime}\left(\bar{x}_{i}\right)} \\
\text { with } \bar{x}_{i}=x_{i}-\frac{f\left(x_{i}\right)}{f^{\prime}\left(\frac{x^{*}+x_{i}}{2}\right)}
\end{gathered}
$$

4. Olver Formula

$$
x_{i+1}=x_{i}-\frac{f\left(x_{i}\right)}{f^{\prime}\left(x_{i}\right)}-\frac{1}{2}\left(\frac{\left[f\left(x_{i}\right)\right]^{2} f^{\prime \prime}\left(x_{i}\right)}{\left[f^{\prime}\left(x_{i}\right)\right]^{3}}\right) \text { (4) }
$$

5. Euler Formula

$$
x_{i+1}=x_{i}-\frac{f\left(x_{i}\right)}{f^{\prime}\left(x_{i}\right)} \cdot \frac{2}{1+\sqrt{1-2 L\left(x_{n}\right)}}
$$

6. Chebyshev Formula

$$
x_{i+1}=x_{i}-\left(1+\frac{1}{2} L\left(x_{n}\right)\right) \cdot \frac{f\left(x_{n}\right)}{f^{\prime}\left(x_{n}\right)}
$$

with $\mathrm{i}=0,1,2, \ldots, x_{i}$ is equation roots to-i, $f^{\prime}\left(x_{i}\right)$ and $f^{\prime \prime}\left(x_{i}\right)$ is the first and second derivative of the function $f$, and $L=\frac{f^{\prime \prime}\left(x_{i}\right) f\left(x_{i}\right)}{f^{\prime}\left(x_{i}\right)^{2}}$.

In the early stages, researchers did the construction of scrip to simulate each method, then the second stage did a comparison of simulated results by looking at the percentage of errors and the number of iterations generated. The research procedure is described in Figure 1 below.

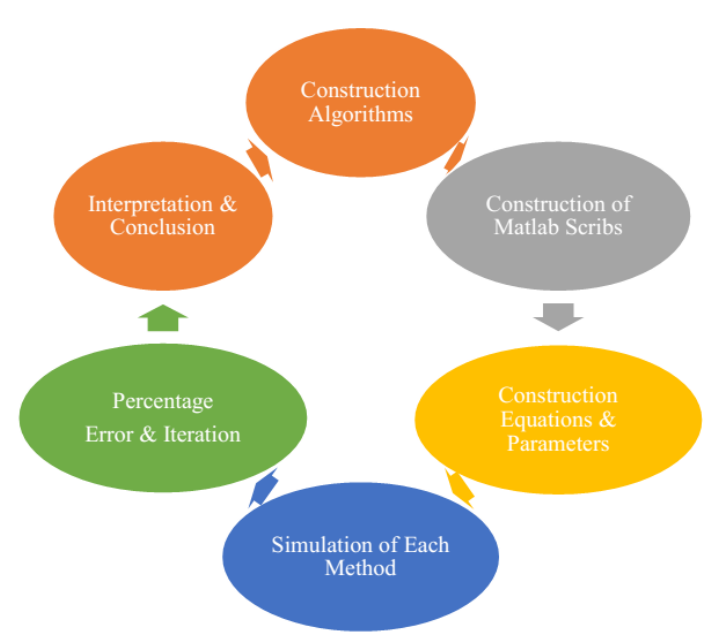

Figure 1. Research Plot
Based on Figure 1 above, it is known that the research phase consists of 6 stages:

1. Construct programming algorithms. At this stage, teams conduct literature studies to find models or equations, equation parameters and compile programming algorithms from each method

2. Construct the MATLAB script or computational algorithms. At this stage, the team transforms the programming algorithm into a computing algorithm in the M-file MATLAB

3. Determine the trial equation. At this stage, the team determines the nonlinear equation that will be determined the roots of the similarity of Wilkinson polynomials and determines the initial $\mathrm{x}$ value.

4. Simulating each method. At this stage, the team performs a simulation of each method for each equation and then records the found root value, the number of iterations, and the percentage of errors given.

5. Calculates the error percentage and the number of iterations. At this stage, the team is comparing the simulation results of each method.

6. Perform interpretations and make conclusions. Based on the results of the error percentages and the number of iterations, then the research team performs an interpretation of the results as well as the method with the percentage of the fewest errors and the fewest number of iterations.

\section{RESULTS AND DISCUSSION}

\section{Initial Conditions}

The issue that will be resolved in this study is to compare the results of each method to determine the roots of Wilkinson's 20-degree polynomial equations. The chart of the Wilkinson equation corresponds to Figure 2 below. 
Desimal, 3 (2), 2020 - 158

Vera Mandailina, Syaharuddin, Dewi Pramita, Malik Ibrahim, Habib Ratu Perwira Negara

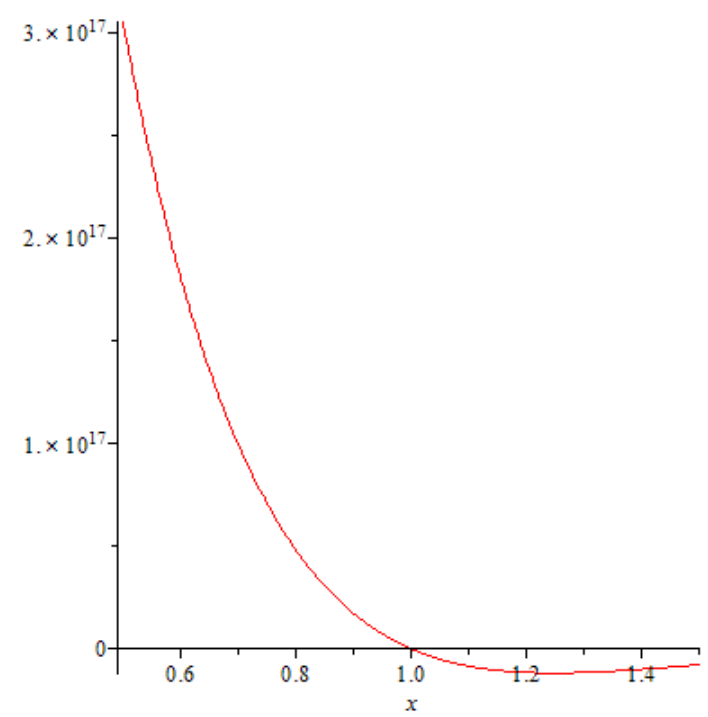

Based on Figure 2 above it appears that one of the roots of the Wilkinson equation is 1 . This is to simplify the process of simulating each method towards the root equation. While the target error is 0.0001 .

\section{M-File MATLAB Each Method}

In this study, we have used the Matlab software to help simulate the iteration of each method. As for the formula M-file each method is presented in Table 1 follows.

Figure 2. Graph $x_{\text {root }}=1$ Wilkinson

Polynomial

Table 1. M-File Each Method

\begin{tabular}{|c|c|}
\hline Method & M-File \\
\hline NR & $\begin{array}{l}\text { x2=x1-(feval(f,x1)/feval(f_diff,x1)); } \\
\text { galat=abs }((x 2-x 1) / x 2) \\
x 1=x 2 ; \\
y=\text { feval(f,x1); }\end{array}$ \\
\hline Halley & $\begin{array}{l}\text { x2=x1-(feval(f,x1)/(feval(f_diff1,x1)- } \\
0.5^{*} \text { feval(f_diff2,x1)*feval(f,x1)/feval(f_diff1,x1)) } \\
\text { galat=abs }((x 2-x 1) / x 2) \\
\text { x1=x2; } \\
\text { y=feval(f,x1); }\end{array}$ \\
\hline $\mathrm{NMH}$ & $\begin{array}{l}\text { xnn=x1-(feval(f,x1)/feval(f_diff1,x1)) } \\
\text { xnb=x1-(feval(f,x1)/feval(f_diff1,0.5*(xnn+x1))); } \\
\text { x2=xnb-((2*feval(f,xnb)*feval(f_diff1,xnb))/(2*feval(f_diff1,xnb)^2- } \\
\text { feval(f,xnb)*feval(f_diff2,xnb)) } \\
\text { galat=abs }((x 2-x 1) / x 2) ; \\
\text { x1=x2; } \\
\text { y=feval(f,x1); }\end{array}$ \\
\hline Olver & $\begin{array}{l}\mathrm{x} 2=\mathrm{x} 1-\left(\mathrm{feval}(\mathrm{f}, \mathrm{x} 1) /\left(\mathrm{feval}\left(\mathrm{f} \_ \text {diff1,x1) }\right)\right)^{-}\right. \\
\left.0.5^{*}\left(\left((\mathrm{feval}(\mathrm{f}, \mathrm{x} 1))^{\wedge} 2^{*} \text { feval(f_diff } 2, \mathrm{x} 1\right)\right) /\left(\mathrm{feval}\left(\mathrm{f} \_ \text {diff } 1, \mathrm{x} 1\right)\right)^{\wedge} 3\right) \\
\text { galat=abs }((\mathrm{x} 2-\mathrm{x} 1) / \mathrm{x} 2) \\
\mathrm{x} 1=\mathrm{x} 2 \\
\mathrm{y}=\mathrm{feval}(\mathrm{f}, \mathrm{x} 1)\end{array}$ \\
\hline Euler & 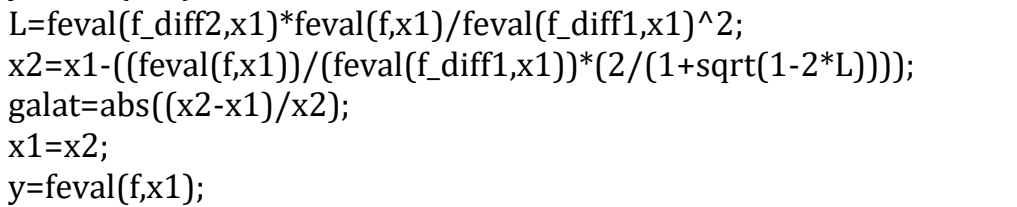 \\
\hline Chebyshev & $\begin{array}{l}\mathrm{L}=\text { feval(f_diff } 2, \mathrm{x} 1)^{*} \mathrm{feval}(\mathrm{f}, \mathrm{x} 1) / \mathrm{feval}\left(\mathrm{f} \_ \text {diff } 1, \mathrm{x} 1\right)^{\wedge} 2 \\
\mathrm{x} 2=\mathrm{x} 1-\left(1+0.5^{*} \mathrm{~L}\right)^{*}\left(\mathrm{feval}(\mathrm{f}, \mathrm{x} 1) / \mathrm{feval}\left(\mathrm{f}_{-} \text {diff } 1, \mathrm{x} 1\right)\right) \\
\text { galat=abs }((\mathrm{x} 2-\mathrm{x} 1) / \mathrm{x} 2) \\
\mathrm{x} 1=\mathrm{x} 2 \\
\mathrm{y}=\text { feval }(\mathrm{f}, \mathrm{x} 1)\end{array}$ \\
\hline
\end{tabular}




\section{Results Simulation}

Furthermore, simulation determines the root of the Wilkinson equation using the M-file that has been constructed. The parameters used are the function $f(x)$, the first derivative $f(x)$, the second derivative $f(x)$, the maximum iteration of 20 , the error of 0.0001 , and the initial $x$ value of 0.5 . The selection of this initial value as a test point the number of iterations towards the equation root is 1 . In fact, in this simulation can be taken another test point, but because to facilitate the result of the iteration value, the value of the function $f(x)$, and the error value calculated. Based on the results of the simulation obtained according to Table 2 follows.

Table 2. Simulation Results of Each

\begin{tabular}{lcccc}
\multicolumn{5}{c}{ Method Phase-1 } \\
\hline \multicolumn{1}{c}{ Method } & $\begin{array}{c}\text { Ite } \\
\text { N }\end{array}$ & $\mathbf{x}_{\mathbf{i}}$ & $\mathbf{f}\left(\mathbf{x}_{\mathbf{i}}\right)$ & Error \\
NR & 7 & 1 & 2,048 & 0.00000008 \\
Halley & 4 & 1 & 14,336 & 0.00002566 \\
NMH & 3 & 1 & 0 & 0.00000000 \\
Olver & 5 & 1 & $-2,048$ & 0.00000007 \\
Euler & 5 & 1 & $-1,024$ & 0.00000955 \\
Chebyshev & 5 & 1 & 0.000 & 0.00000007 \\
\hline
\end{tabular}

Table 2 indicates that the Newton Midpoint Halley method has the highest level of accuracy. Also, this method is also the fastest method converging to point $\mathrm{x}=$ 1 with iterations of 3 . While the other method according to the convergence towards the root of the equation is Halley was 4 iterations, the Chebyshev method was 5 iterations, the Olver method was 5 iterations, the Euler method was 5 iterations, and Newton-Raphson method was 7 iterations. So the following convergence sequence is obtained:

$$
x_{3} \mathrm{NMH}>x_{4} H>x_{5} \mathrm{C}>x_{5} \mathrm{O}>x_{5} E>x_{7} N R
$$

However, in this iteration, only Newton Midpoint Halley and Chebyshev methods have reached $f(x)=0$, while the other method is still $f(x) \neq 0$. So when the error is raised to 0.000000001 , then the result is $\mathrm{f}$ $(\mathrm{x})=0$ on the Halley method in the 5th iteration, Halley and Olver method in the 6th iteration, and Newton-Rapshon method in the 9th iteration. This simulation result is Phase 2 which aims to determine the value $\mathrm{f}(\mathrm{x})=0$ with the error parameter changes and the number of iterations according to Table 3 follows.

Table 3. Simulation Results of Each Method Phase-2

\begin{tabular}{lcccc}
\hline \multicolumn{1}{c}{ Method } & Iter & $\mathbf{x}_{\mathbf{i}}$ & $\mathbf{f}\left(\mathbf{x}_{\mathbf{i}}\right)$ & Error \\
NR & 9 & 1 & 0.000 & 0.000 \\
Halley & 5 & 1 & 0.000 & 0.000 \\
NMH & 3 & 1 & 0.000 & 0.000 \\
Olver & 6 & 1 & 0.000 & 0.000 \\
Euler & 6 & 1 & 0.000 & 0.000 \\
Chebyshev & 5 & 1 & 0.000 & $7,54 \times 10^{-7}$ \\
\hline
\end{tabular}

The above simulation results, proving that the method which is a derivative of the Taylor series of two orders is faster towards the convergence point than the Newton-Raphson method that is a derivative of the Taylor series of one order. But in reality in the field, this method is most popular, because it only needs the first derivative to specify the value $\mathrm{f}(\mathrm{x})=0$ with the least error possible.

The results of the research Darmawan \& Zazilah (2019) mentions that the Olver and Halley methods are more accurate with fewer iterations of the NewtonRaphson method proved to be true. However, a combination of NewtonRaphson method, Halley's method, and Midpoint method, known as Newton Midpoint Halley's method, was more of new insight. Due to simulated results by combining the computational algorithm several methods are able to provide faster and maximal results.

Nowadays, the development of technology with the face of a reliable computing system is certainly not the level of complexity seen, but the level of accuracy and time to be minimal to the output of the compute is very accurate. So 
that in the future, these methods should be conveyed in the course of lecturing with students. So that students have many options with a more accurate method of resolving computational mathematical issues numerically.

\section{CONCLUSIONS AND SUGGESTIONS}

Testing various methods in case of non-linear equations can be used as a benchmark in solving some cases in the future and can be applied in a lecture system in applied mathematics or other fields that discuss the same topic. Similar to the Newton-Raphson method which is the most popular formula taught to students, but the results of this study proved that the method of Newton Midpoint Halley method which is a combination of Newton-Raphson method and Halley methods is much faster and Accurate in resolving Wilkinson polynomial. Similarly Halley's methods are more accurate than the methods Chebyshev, Olver and Euler method. While the Newton-Raphson method is the most needed method of iteration than other methods. Based on research basil, in the future it is necessary to develop the materials for computational numerical methods to be delivered to students in colleges. Teaching these derived methods of the Taylor series will be very beneficial for other researchers in the applied for non-linear issues. It also does not close the possibility to develop a new formula either a combination of existing methods algorithms as well as new findings later.

\section{REFERENCES}

Alexandrov, S. (2018). Numerical method. In SpringerBriefs in Applied Sciences and Technology (pp. 61-80). https://doi.org/10.1007/978-98110-5227-9_5

Bakery, A. A., \& Elmatty, A. R. A. (2017). Non linear difference equation of orlicz type. Journal of Computational and Theoretical Nanoscience, 14(1), 306-313.

https://doi.org/10.1166/jctn.2017.6 321

D. A. Pratamasyari, Silalahi, B. P., \& Guritman, S. (2017). Kombinasi Varian Metode Newton dan Metode Halley untuk Menyelesaikan Persamaan Tak Linear. Journal of Mathematics and Its Applications, 16(2), 1-14.

Darmawan, R. N., \& Zazilah, A. N. (2019). Perbandingan Metode Halley dan Olver dalam Penentuan Akar-akar Penyelesaian Polinomial Wilkinson. JTAM Uurnal Teori Dan Aplikasi Matematika), 3(2), 93-97.

Hakim, L., \& Habibi, A. R. (2016). Perbandingan Skema Numerik Metode Finite Difference dan Spectral. Jurnal Ilmiah Teknologi Informasi Asia, 10(2), 34-40.

Hasa, R., \& Radoš, R. (2015). Numerical matlab solvers in automotive simulation. APLIMAT 2015 - 14th Conference on Applied Mathematics, Proceedings, 346-356.

Krag, B. (2017). Modeling and simulationbasics and benefits. In In-Flight Simulators and Fly-by-Wire/Light Demonstrators: A Historical Account of International Aeronautical Research (pp. 19-25). https://doi.org/10.1007/978-3-31953997-3_3

Lim, H. C., Shin, H. S., Lim, H. C., \& Shin, H. S. (2013). Non-Equation-Based Models. In Fed-Batch Cultures (pp. 121-134). https://doi.org/10.1017/cbo978113 9018777.008

Negara, Habib Ratu Perwira; Kurniawati, Kiki, R. S. (2018). Design GUI of simulation and numerical solution of equation and non linier equation systems. Jurnal Riset Teknologi Dan Inovasi Pendidikan (JARTIKA), 1(2), 90-98.

Nur, A. M. (2018). Pengaruh Aplikasi C\# 
Desimal, 3 (2), 2020 - 160

Vera Mandailina, Syaharuddin, Dewi Pramita, Malik Ibrahim, Habib Ratu Perwira Negara

dalam Proses Perhitungan Numerik Terhadap Solusi Persamaan Non Linier. Jurnal Informatika Dan Teknologi, 1, 82.

Schmidt, J. D. (2010). Numerical simulation of optical wave propagation: With examples in MATLAB. In Numerical Simulation of Optical Wave Propagation: With Examples in MATLAB. https://doi.org/10.1117/3.866274

Tentua, M. N. (2017). Aplikasi Analisis Tingkat Akurasi Penyelesaian Persamaan Non Linier Dengan Metode Biseksidan Metode Newton
Raphson. Jurnal Dinamika Informatika, 6(2), 113-132.

Wigati, J. (2017). Solusi Numerik Persamaan Non-Linier Dengan Metode Bisection dan Regula Falsi. $G$ Tech : Jurnal Teknologi Terapan, 1(1), 5-17. Retrieved from http://ejournal.uniramalang.ac.id/in dex.php/g-tech/article/view/262

Wilson, C. L. (2011). Mathematical modeling, clustering algorithms and applications. In Mathematical Modeling, Clustering Algorithms and Applications. 